\title{
DAS ABKOMMEN VON JAUNDE II IN KAMERUNISCHER SICHT
}

Am Nachmittag des 29. Juli 1969 wurde im Sitzungssaal der kamerunischen Nationalversammlung in Jaunde das zweite Assoziierungsabkommen von 18 meist frankophonen afrikanischen Staaten, der EWG und ihren sechs Mitgliedstaaten unterzeichnet. Es wird voraussichtlich in der nächsten Zeit ratifiziert werden.

Der wesentlichste Grund für die Wahl von Jaunde als Unterzeichnungsort auch der neuen Konvention dürfte gewesen sein, daß die kamerunische Regierung bereit und in der Lage war, die zahlreichen Delegationen repräsentativ für Afrika zu empfangen. Hinzu kommt, daß Jaunde Sitz der OCAM (Organisation commune Africaine et Malagache) ist, und daß Kamerun politisch zu den stabilsten Ländern Afrikas zählt.

Es ist daher interessant, die Unterzeichnung des neuen Abkommens aus kamerunischer Sicht $z u$ betrachten. Neben der Rede, die der allgemein anerkannte Staatspräsident Ahidjo anläßlich der Unterzeichnung vor den Vertretern von 24 Ländern gehalten hat, konnte der Verfasser auch die Reaktion der Bevölkerung, die am Straßenrand winkend die Zeremonien verfolgte, in seine Uberlegungen einbeziehen.

Wie überall auf der Welt, ist es für den jungen Staat Kamerun eine besondere Genugtuung, wenn mehrere europäische Minister, der Präsident und ein Mitglied der EWG-Kommission an der Spitze von mehrköpfigen Delegationen kommen, um ein Abkommen zu unterzeichnen. Obwohl wegen der schwierigen Flugverbindungen auch zahlreiche afrikanische Delegationen über Paris anreisen mußten, hat hier niemand nachgerechnet, wieviel billiger eine Unterzeichnung in Europa gekommen wäre. Für die Ehrung durch die Unterzeichnungszeremonie in Afrika ist man gewillt, einiges zu geben.

Ein Europäer versucht in erster Linie die wirtschaftlichen Konsequenzen des Abkommens zu sehen. Für die Afrikaner und besonders die Kameruner ist zunächst psychologisch maßgebend, daß sie im Abkommen als gleichberechtigte Partner behandelt werden. Zwar weiß man auch hier, daß bei den Verhandlungen in Brüssel die wesentlichste Frage war, auf welche Bedingungen sich die sechs einigen würden, und die Assoziierten dann mehr oder minder vor die Wahl gestellt waren, zu akzeptieren oder nicht. Sehr entscheidend für die Afrikaner war es aber, daß sie nicht erst eingeladen wurden, als alles beschlossen war. Dennoch sind sie sich klar, daß sie eigentlich Hilfsbedürftige sind, aber sie sind ja schon Assoziierte und sie wurden, wie auch die Wahl des Unterzeichnungsortes zeigt, als vollwertige Partner behandelt.

Die wirtschaftlichen Fragen interessieren die breite Ơffentlichkeit zunächst noch weniger. Hier ist klar, daß die wirtschaftliche Überlegenheit Europas groß ist; hinzu kommt, daß die Kameruner - von einigen Ausnahmen abgesehen - noch nicht so smarte und geschäftstüchtige Kaufleute sind wie die Europäer (der hiesige Handel ist noch immer weitgehend von Franzosen, Libanesen und Griechen beherrscht). Man hat daher Zweifel, ob die Entwicklungsländer nicht „auf ewig“ ihre Rolle in der Lieferung von landwirtschaftlichen und mineralischen Rohstoffen finden müssen. Man weiß hier, daß der Handel mit den EWG-Staaten im Grunde stagniert, ist aber angesichts der noch unterentwickelten Vermarktung auf ihn angewiesen (zwei Drittel des Außenhandels).

Finanziell wirkt sich der Vertrag für Kamerun wie folgt aus: (Zahlen errechnet nach Außenhandelsstatistik 1968). 
Die EWG-Länder gewähren auf einige Hauptausfuhrgüter Kameruns Präferenzen von im Durchschnitt ca. 6 Prozent, verzichten also bei einem kamerunischen EWG-Export von ca. 500 Mio. DM auf Zölle im Betrag von ca. 30 Mio. DM pro Jahr.

Kamerun gewährt eine Präferenz von im Durchschnitt 15 Prozent, verzichtet also bei einem EWG-Import von ca. 490 Mio. DM auf Zolleinnahmen von ca. 70 Mio. DM jährlich.

Die Differenz zwischen der absoluten Höhe der Zollprivilegien wird durch die Leistungen aus dem EWG-Entwicklungsfonds ausgeglichen, aus dem Kamerun in den vergangenen Jahren durchschnittlich 40 Mio. DM erhalten hat.

Die afrikanischen Forderungen nach höherer Dotierung des für sie besonders wichtigen Entwicklungsfonds beruhen auf der Annahme, daß der Außenhandel in den nächsten Jahren zunimmt und die Differenz zwischen den afrikanischen und EWG-Präferenzen sich noch vergrößert.

Die kamerunische Staatsführung ist sich aber im klaren, daß zusätzlich zu der Entwicklungshilfe aus dem EWG-Fonds, der Hauptlieferant und Hauptnutznießer Frankreich und auch andere EWG-Staaten erhebliche Entwicklungshilfe-Leistungen aufbringen, die für die Entwicklung des Landes gezielter eingesetzt werden können, als die entgangenen Zolleinnahmen. Dem einfachen Mann auf der Straße sind diese Zusammenhänge natürlich nicht geläufig. Er rechnet auf Entwicklungshilfe, ebenso wie hier in der afrikanischen Großfamilie der arme Bruder auf die Unterstützung des reicheren zählen kann. Die kamerunische Regierung ist sich weiter bewußt, daß bei Wegfall der Präferenzen der (von kamerunischer Seite besteuerte) Export mangels Konkurrenzfähigkeit erheblich absinken würde, während der Import von Luxus- und entwicklungsnotwendigen Gegenständen ohne drastische Einschränkungen nicht nennenswert gesenkt werden könnte. Der Vertrag ist mithin äußerst wichtig, um Kameruns Außenhandel und den zu ca. 80 Prozent auf Außenhandelsabgaben basierenden Staatshaushalt im Gleichgewicht zu halten.

Das wesentlichste Ungleichgewicht im europäisch-afrikanischen Handel vermindert der Vertrag jedoch nicht. Die hochentwickelte europäische Landwirtschaft wird vor dem Weltmarkt geschützt, die unterentwickelte afrikanische jedoch nicht (was nicht ganz zutrifft, siehe die Präferenzen).

Die Preisbildung durch Angebot und Nachfrage wird auch hier als unsozial bezeichnet. Die afrikanischen Länder brauchen Maschinen, müssen sie also auch kaufen, wenn sie auf dem europäischen Markt teurer werden. Die Europäer haben genug Nahrungsmittel und können sich aussuchen, wer ihnen Kakao oder Kaffee am billigsten liefert. Die europäischen Handelsgesellschaften machen dabei noch erhebliche Gewinne, die meist noch nicht einmal in Kamerun versteuert werden. Ziel der Kameruner ist (auch mit Hilfe des durch den EWG-Entwicklungsfond bereitgestellten billigen Kapitals), eine Veredelungsindustrie an Ort und Stelle aufzubauen, so daß ein Teil der Gewinne im Lande bleibt.

Man macht sich hier nicht die Hoffnung und setzt sich nicht das Ziel einiger sozialistischer afrikanischer Länder, man könne das System des Welthandels sowie die hohen Zinssätze am freien Kapitalmarkt ändern. Die Kameruner wissen, daß sie wirtschaftspolitisch noch einige Zeit am schwächeren Hebel sitzen und sind daher bereit, die Konvention als „humanitären Akt im Geist von New-Delhi“ anzuerkennen. 